\title{
Aplicação das ferramentas da qualidade em uma empresa de serviços de saúde da região metropolitana do Recife-PE
}

Quality tools placed in a healthcare services company at surrounding area of Recife-PE

\section{Rodrigo Felix da Silva ${ }^{1}$}

\author{
Ana de Fátima Braga Barbosa ${ }^{1}$ \\ ${ }^{1}$ Escola Politécnica de Pernambuco, Universidade de Pernambuco, Recife, Brasil, \\ E-mail do autor principal: Rodrigo Felix da Silva rodrigo.r.fs@hotmail.com
}

\section{Resumo}

Com o aumento da demanda de terceirização dos serviços na área de saúde, tanto em hospitais quanto em residências, home care (cuidados em casa), as empresas prestadoras de serviços e os consumidores que aderem a estes, ficaram muito mais exigentes no intuito de melhorar os processos e/ou produtos com qualidade, almejando uma satisfação das duas partes. Para que as empresas sobrevivam a este modelo é necessário adotar métodos de qualidade, ou seja, ter uma Gerência da Qualidade Total, usualmente conhecida por Total Quality Management (TQM). Diante disso tudo, surge a necessidade de utilizar um método tendo como base o ciclo PDCA, que significa planejar, fazer, checar e agir na correção dos processos. Desta maneira tem-se uma grande versatilidade para resolução de problemas ou proporcionar melhorias dentro de um ambiente de trabalho, onde a quantidade de informações disponíveis pode ser extremamente grande e o tempo de compartilhamento reduzido. Este artigo foi elaborado com base em um estudo de caso que, com algumas aplicações desta técnica de melhoria, teve como consequência nos processos uma grande satisfação das duas partes. O referido estudo foi realizado em uma empresa que presta serviço na área de saúde, situada na região metropolitana do Recife, e tornou possível solucionar problemas desde a sua causa raiz. A aplicação das principais ferramentas da qualidade, como melhoria nos processos das atividades rotineiras, foi imprescindível para o crescimento da empresa.

Palavras-Chave: Gerência da Qualidade Total; PDCA; Ferramentas da Qualidade; Empresa de serviços.

\section{Abstract}

With the increasing demand for outsourcing of health services, both hospitals and homes, home care, service providers and consumers who adhere to them, have become much more demanding in order to develop the processes and / or products with quality, aiming the satisfaction of the two parties. For companies to survive this model it was necessary to adopt quality methods, that is, to have a Total Quality Management, usually known as TQM. Given all this, the need arises to use a method based on the PDCA cycle, which means to plan, do, check and act on the correctness of the processes. This way there is great versatility to solve problems or provide improvements within a workplace where the amount of information available can be extremely large and sharing time is reduced. This article was elaborated on the basis of a case study that, with some applications of this improvement technique, had as a consequence in the processes a great satisfaction of both parties, this study was 
held in a company that provides service in the health area, located in the metropolitan area of Recife, and has made it possible to solve problems since its root cause. The application of the main quality tools as an improvement in the processes of routine activities was essential for the growth of the company.

Key-words: Total Quality Management; PDCA; Quality tools; Company services.

\section{Introdução}

A procura pelo aumento de produtividade e qualidade, produzir mais com menos esforços e reduzindo os custos, tem sido, por longo tempo, um dos principais objetivos das empresas.

Este assunto, por ser de suma importância, vem impulsionando as empresas a buscarem técnicas de qualidade e melhoria nos processos para obtenção de maior velocidade na produção de bens e serviços.

Uma Cooperativa de prestação de serviços na área de saúde especializada nos cuidados em casa, situada na Região Metropolitana do Recife, que se permitiu aplicar o método do TQM em companhia de algumas ferramentas da qualidade, iniciou suas atividades em 1999 e vem se mantendo no mercado pernambucano com profissionais capacitados para atender seus clientes com qualidade e segurança.

Através da análise e verificação dos problemas no setor Departamento Pessoal e Financeiro, percebeu-se que os métodos utilizados para realização de certos tipos de tarefas como: armazenamentos de dados pessoais, procedimentos, processos, informações gerenciais, não eram aplicados de forma adequada. Com isso, fez-se necessário um maior monitoramento e controle dos serviços, tornando complexa a operação para chegar a uma ferramenta que melhorasse todo o controle do setor.

Um dos grandes problemas encontrados pelos profissionais que atuam neste setor foi: lentidão no processo de execução das tarefas e grande quantidade de papéis impressos e arquivados, gerando acúmulo de documentos financeiros e de pessoal.

Muitos perceberam que não existia padronização entre os níveis das atividades, perdia-se muito tempo em consolidar as informações, desde a entrada (inputs) a serem transformados até a saída (outputs) e dificuldades de controle financeiro mais preciso.

Neste contexto, como proceder para que fosse possível obter um maior monitoramento e controle dos processos e das informações deste setor?

Este trabalho, demonstra através da análise e verificação dos problemas em uma empresa de serviços de saúde, especificamente nos setores Departamento Pessoal e Financeiro, possibilitar melhorias por meio das ferramentas da qualidade. E, com a aplicação do TQM, junto com a ferramenta PDCA obter os resultados esperados e utilizar o Kaizen (melhoria contínua). A Cooperativa de serviços necessitou de um maior monitoramento e controle dos serviços, tornando complexa a operação de chegar a uma ferramenta da qualidade que melhorasse todo o controle do setor.

\section{Objetivos}

\subsection{Geral}

Analisar o setor Departamento Pessoal e Financeiro após a aplicação das principais ferramentas da qualidade: Gráfico de Pareto, Diagrama de Causa e Efeito, 5W2H e demonstrar a melhoria nas suas rotinas.

\subsection{Específicos}

- Mostrar um breve histórico e as teorias das ferramentas da qualidade.

- Detectar problemas no setor Departamento Pessoal e Financeiro.

- Aplicar e executar as ferramentas da qualidade nos problemas apresentados.

- Obter os resultados esperados e utilizar o Kaizen (melhoria contínua). 


\section{Revisão da Literatura}

\subsection{Origem da Qualidade}

Para saber um pouco de qualidade, é preciso passar pela história e sua evolução, desde o surgimento até os dias de hoje.

O artesão era um especialista que tinha domínio completo de todo o ciclo de produção, desde a concepção do produto até o pós-venda. Nessa época, o cliente estava próximo do artesão, explicitando suas necessidades, as quais o artesão procurava atender, pois sabia que a comercialização de seus produtos dependia muito da reputação do produto final, que, naquele tempo, era comunicada boca a boca pelos clientes [1].

Embora a gestão da qualidade seja um assunto que ganhou grande notoriedade a partir do início da década de 1980, não se trata, contudo, de uma invenção moderna. Podemos narrar a história de muitas e variadas formas. Um grande número de especialistas concorda que o conceito ou a filosofia da essência existe desde há muito, discordando somente quanto ao seu início. Em relação a este ponto os seus argumentos variam, sustentando uns que o conceito existe desde algumas centenas de anos e outros falam em milhares de anos [2].

Conforme fora mencionado por António e Teixeira [2], a natureza tem sua origem datada já a partir do ano de 1200 como mostrado na Figura 1 , em que já se praticava a qualidade que teve seu início com Guilds na Europa Medieval, onde eram feitas inspeções nos principais produtos comercializados na época, e com o passar dos anos ela vem se desenvolvendo cada vez mais.

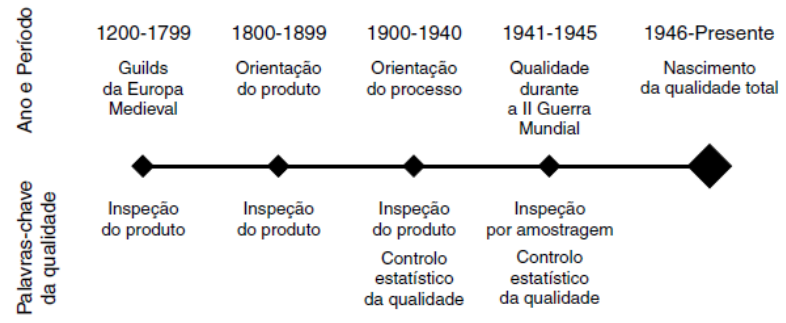

Figura 1: Uma perspectiva do desenvolvimento da qualidade.

Fonte: [2]

\subsection{Gerência da Qualidade Total - TQM}

A Gerência da Qualidade Total, usualmente conhecida por Total Quality Management (TQM), tem sua origem datada de 1949; nesta época o
Sindicato dos Cientistas e Engenheiros do Japão, formaram uma equipe de pessoas estudiosas, engenheiros e funcionários governamentais com objetivos de melhorar a qualidade e a produtividade pós-guerra. Segundo Moreira [3], TQM é uma filosofia gerencial, isto é, uma forma particular de enxergar uma instituição, para que ela serve e como administrá-la. De uma forma mais completa, TQM é uma filosofia integrada de gerência e um conjunto de práticas que enfatiza a melhoria contínua, a busca pelo entendimento das necessidades do cliente, o pensamento de longo prazo, a eliminação de refugo e retrabalho, envolvimento do trabalhador, trabalho em equipe, novos projetos do processo, benchmarking (busca e adoção das melhores práticas conhecidas de trabalho), análise e solução de problemas pelos empregados, medida de resultados e relacionamento próximo com fornecedores.

O TQM é um método de gestão da qualidade que tem o foco em fazer hoje melhor do que ontem e fazer amanhã melhor que hoje, para a satisfação do cliente interno e externo utilizando os cinco pilares de sobrevivência QCAMS (qualidade, custo, atendimento, moral e segurança), e tendo como base a melhoria contínua, o ciclo PDCA (planejar, fazer, checar e agir). É um método de gestão para alcançar metas de melhoria, sendo uma das ferramentas da qualidade de solução de problemas e melhoria dos processos, juntamente com as principais ferramentas de qualidade, sendo elas: Gráfico de Pareto, Diagrama de Causa e Efeito, $5 \mathrm{~W} 2 \mathrm{H}$ - what, why, where, when, who, how e how much (o que, por quê, onde, quando, quem, como e quanto): como planos de ação.

Segundo Moreira [3], qualidade é entendida normalmente como um atributo de produtos ou serviços, mas pode referir-se a tudo que é feito pelas pessoas; fala-se na qualidade de um aparelho elétrico, de um carro, do serviço prestado por um hospital, do ensino provido por uma escola, ou trabalho de um funcionário ou departamento.

A noção de administração da qualidade total foi introduzida por Feigenbaum em 1957. Mais recentemente, tem sido desenvolvida por meio de várias abordagens amplamente conhecidas, introduzidas por vários gurus da qualidade, como Deming, Juran, Ishikawa, Tagushi e Crosby [4].

Foi através destes estudiosos que se deu a origem do conceito da Gerência da Qualidade Total, e conforme define Feigenbaum [5], TQM é um

http: / / dx.doi.org/10.25286/repa.v2i4.750 
sistema eficaz para integrar as forças de desenvolvimento, manutenção e melhoria da qualidade dos vários grupos de uma organização, permitindo levar a produção e o serviço aos níveis mais econômicos da operação e que atendam plenamente à satisfação do consumidor.

\subsection{Cíclo PDCA}

Desenvolvido por Shewhart em colaboração com seu companheiro de pesquisas no Laboratório Bell, W. Edwards Deming, em 1930, o Ciclo PDCA foi estruturado a partir de quatro etapas: planejar (Plan), executar (Do), verificar (Check) e atuar $(A c t)$ e é constituído por questionamentos repetidos dos detalhados processos de uma operação [6].

O ciclo PDCA é um método muito utilizado para atingir e manter metas. Portanto, este ciclo sempre tem que girar no sentido horário mostrando de forma simples a melhoria constante.

A Figura 2, representa do ciclo PDCA, para atingir as metas que proporcionam melhorias nos processos e produtos [7].

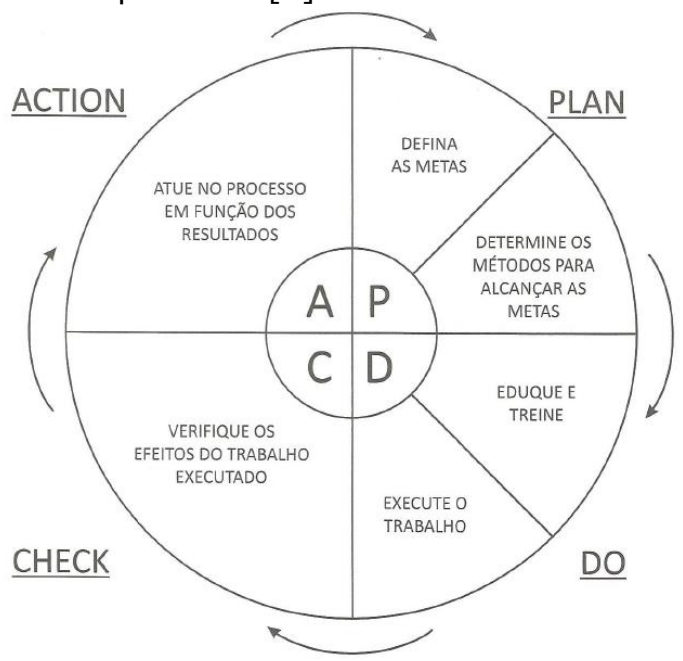

Figura 2: PDCA - Método de Gerenciamento de Processo.

Fonte: [7]

Chaib [8], descreve cada uma das partes do método da seguinte forma:

Plan (Planejar): estabelecer os objetivos e processos necessários para fornecer resultados de acordo com os requisitos do cliente e políticas da organização;

Do (Fazer): implementar os processos;
Check (Checar): monitorar e medir processos e produtos em relação às políticas, aos objetivos e aos requisitos para o produto e relatar os resultados;

Act (Agir): executar ações para promover continuamente a melhoria do desempenho do processo.

\subsection{Ferramentas da Qualidade}

A qualidade, como significado amplo, é buscada por todos os indivíduos; estes, ao adquirirem um bem ou serviço, acreditam que estão comprando algo com qualidade, que atenda todas as suas necessidades. Na área organizacional busca-se a satisfação dos clientes e isso só acontece quando se produz com qualidade. Empresas que buscam a excelência no seu ramo de atuação constantemente utilizam técnicas de qualidade, aperfeiçoando os seus processos, reduzindo os desperdícios e buscando a melhoria contínua, tendo como resultado um produto eficiente $e$ sustentável [9].

\subsubsection{Diagrama de Causa e Efeito}

Os diagramas de causa-efeito são um método, particularmente, efetivo de ajuda para pesquisar as raízes de problemas. Eles fazem isso perguntando as mesmas questões: "o que", "onde", "como" e "por que", mas desta vez acrescentando algumas respostas possíveis de forma explícita. Eles também podem ser usados para identificar áreas em que são necessários mais dados. Os diagramas de causa-efeito (também são conhecidos como diagramas de espinha de peixe ou diagramas Ishikawa) tornaram-se extensivamente usados em programas de melhoramentos [5].

O Diagrama de causa e efeito, também chamado de $6 \mathrm{M}$, é utilizado para definir o problema, que é desenhado por uma seta e na extremidade contém o problema em questão, que no caso é o efeito e está ligado por seis setas representadas por fatores básicos das causas: mão de obra, método, máquina, meio ambiente, medição e material. Para analisar mais a fundo e descobrir a origem das causas é feito um brainstorming (tempestade de ideias), coletando informações para possibilitar as soluções para o problema. A Figura 3 mostra de forma geral o problema e suas causas. 


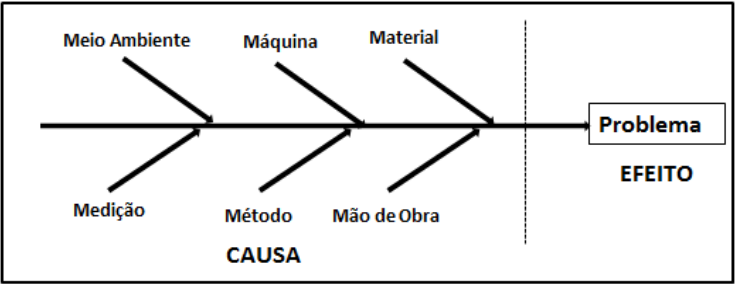

Figura 3: Diagrama de Ishikawa/Causa e Efeito/Espinha de Peixe.

Fonte: adaptado pelo autor do [5]

\subsubsection{Plano de Ação}

Após a montagem do diagrama de causa e efeito e identificação dos possíveis problemas, neste caso deve-se realizar um plano de ação, usando a metodologia elaborada por planilhas 0 5W2H - (what, why, where, when, who, how, how much): "o que", "quem", "quando", "onde", "quanto", "por quê", "como". Com as seguintes informações: o que será feito, por que será feito, onde será feito, quando será feito, por quem será feito, quando será feito, como será feito, quanto custará fazer.

A ferramenta $5 \mathrm{~W} 2 \mathrm{H}$ foi criada por profissionais da indústria automobilística do Japão como uma ferramenta auxiliar na utilização do PDCA, principalmente na fase de planejamento. Polacinski descreve que a ferramenta consiste num plano de ação para atividades pré-estabelecidas que precisem ser desenvolvidas com a maior clareza possível, além de funcionar como um mapeamento dessas atividades. O autor continua discorrendo e ressalta que o objetivo central da ferramenta $5 \mathrm{~W} 2 \mathrm{H}$ é responder a sete questões e organizá-las [10].

\section{- Procedimentos operacionais}

O procedimento descreve o passo a passo de como devem ser executadas certas tarefas rotineiras de uma forma padronizada. Isso proporciona um efeito que todos os produtos ou serviços sejam iguais.

De acordo com Falconi [11], é preciso definir o nível de controle que precisa ter e os métodos ou procedimentos a serem adotados por todos da organização com o intuito de melhorar o fluxo do trabalho, estabelecendo assim, um planejamento de qualidade.

\section{Metodologia}

Foi feito uma revisão bibliográfica com elementos extraídos da obra dos autores mencionados, baseando-se nos conhecimentos dos teóricos selecionados.

O estudo foi realizado em uma cooperativa prestadora de serviços médicos e áreas afins, com o objetivo de solucionar alguns problemas no setor de Departamento Pessoal e Faturamento. A empresa está localizada na Região Metropolitana do Recife onde presta serviços em domicílios e hospitais.

Através da análise e verificação dos problemas diante dos setores foi aplicado o TQM de início, junto com as ferramentas da qualidade, possibilitando melhorias.

Foram utilizadas as seguintes ferramentas da qualidade: brainstorming, gráfico de Pareto, diagrama de causa e efeito e $5 \mathrm{~W} 2 \mathrm{H}$.

\section{Resultados e Discussões}

A empresa de pequeno porte que atua desde 1999 no mercado de serviços de saúde, com o passar dos anos teve um crescimento no faturamento e no número de colaboradores que atuam externamente. $\mathrm{Na}$ Figura 4 foram demonstrados estes dados de um dos contratos existente e com estas informações começaram também a surgir alguns problemas, em agosto de 2016 houve uma grande necessidade de aplicação do TQM, juntamente com algumas ferramentas da qualidade para identificar problemas e obter soluções.

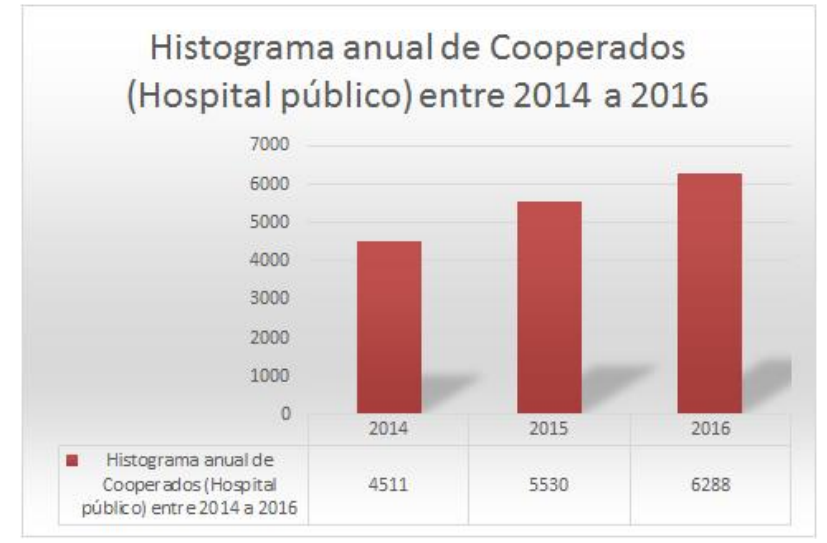

Figura 4: Acompanhamento do histograma acumulado anual

Fonte: autor

Primeiramente foram identificados vários problemas dentro do setor com a aplicação do diagrama de Pareto, onde $80 \%$ das consequências vem de $20 \%$ das causas. Para isto, foi verificado uma lista de ocorrências com os problemas

http: / / dx.doi.org/10.25286/repa.v2i4.750 
apresentados conforme a Figura 5.

\begin{tabular}{|l|c|c|}
\hline \multicolumn{1}{|c|}{ Razões } & $\begin{array}{c}\text { Número de } \\
\text { ocorrências }\end{array}$ & $\begin{array}{c}\% \\
\text { Unitário }\end{array}$ \\
\hline $\begin{array}{l}\text { Demonstrativos de } \\
\text { produtividades } \\
\text { errados }\end{array}$ & 18 & $38 \%$ \\
\hline $\begin{array}{l}\text { Soma das folhas de } \\
\text { frequência erradas }\end{array}$ & 15 & $31 \%$ \\
\hline $\begin{array}{l}\text { Duplos } \\
\text { demonstrativos de } \\
\text { produtividade }\end{array}$ & 11 & $23 \%$ \\
\hline $\begin{array}{l}\text { O não recolhimento } \\
\text { das folhas de } \\
\text { frequências }\end{array}$ & 4 & $8 \%$ \\
\hline Total & 48 & $100 \%$ \\
\hline
\end{tabular}

Figura 5: Lista de ocorrência no setor Fonte: autor

As razões organizadas em uma tabela, com os seus respectivos percentuais calculados, tornaram possível visualizar e sequenciar as ocorrências, priorizando as de maior percentual.

Com os dados apresentados na Figura 5, foi possível construir o gráfico de Pareto, recurso utilizado para ordenar as suas causas de perdas que devem ser resolvidas. Sendo assim, na Figura 6 , apresenta-se de forma mais clara e auxiliando na identificação dos problemas, priorizando-os para que sejam resolvidos de acordo com seu grau de relevância.

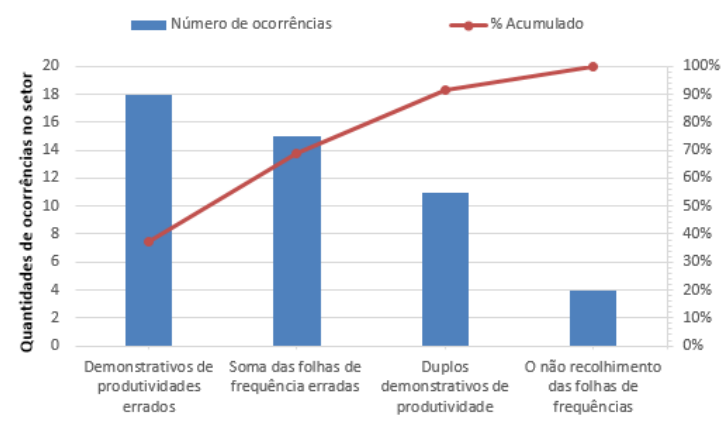

Figura 6: Diagrama de Pareto para solução dos problemas mais críticos

Fonte: autor

Como mostrado na Figura 6, ficou bem mais visível identificar as causas ou problemas, possibilitando a concentração de esforços, e para saná-las foi feito um brainstorming com os colaboradores internos colocando as suas ideias referentes ao setor, com isso foi elaborado o diagrama de causa e efeito conforme a Figura 7.

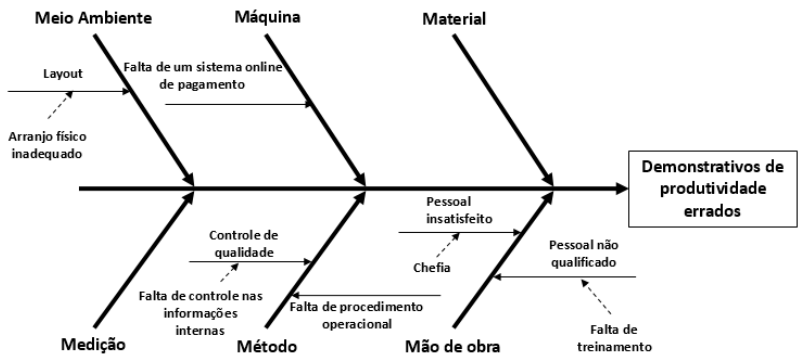

Figura 7: Diagrama de causa e efeito dos demonstrativos de produtividades errados

Fonte: Adaptado de [5]

Foram identificadas, como apresentado na Figura 4, as possíveis causas: mão de obra não qualificada, assim como a falta de treinamento, ocasionando a má organização; colaboradores insatisfeitos devido à chefia rígida e resistente a mudanças, provocando assim uma certa instabilidade emocional em alguns colaboradores que se sentiam pressionados e desvalorizados; o método de trabalho utilizado, a falta de mapeamento dos processos, levando a uma não padronização de tarefas e a falta de controle na qualidade das informações; o ambiente organizacional, a falta de organização no layout do setor; e no que concerne a máquinas, o sistema informacional e os computadores utilizados estavam obsoletos.

Com esta análise do diagrama de causa e efeito, foi elaborado um plano de ação para corrigir as causas e sanar o problema, neste caso usando a ferramenta da planilha e com as informações colocadas no 5W2H - (what, why, where, when, who, how, how much): "o que", "por quê", "onde", "quando", "quem", "como", "quanto". A planilha se encontra no Apêndice 1, com as seguintes informações: o que será feito, por que será feito, onde será feito, quando será feito, por quem será feito, quando será feito, por quem será feito, como será feito, quanto custará fazer.

A primeira causa foi: pessoal não qualificado. Devido a isto, existiam erros grosseiros, e até alguns graves, como: efetuava-se pagamentos trocados, por exemplo, cooperado de nome $A$ recebia o pagamento do cooperado de nome $B$, que eram feitos via cheque, visto que apresentavam mesmo nome e sobrenome e isso gerava um desgaste interno e externo, havendo casos de se pagar duas vezes a mesma pessoa e, na maioria das vezes, não eram feitas anotações ou 
treinamentos para o não acontecimento futuro dos mesmos erros.

Para resolver esta questão foi realizada uma reunião com os colaboradores apresentando-lhes estas dificuldades e, como solução, foram feitos treinamentos semanais para que as informações fossem passadas a todos os colaboradores do setor, para haver um entendimento melhor entre eles, fazendo boas práticas e tornando-os capacitados.

Os treinamentos realizados foram:

- Segurança da informação: está diretamente relacionada com proteção de um conjunto de informações, no sentido de preservar o valor que possuem para um indivíduo ou uma organização.

- O poder do hábito: fazer com os outros, o que desejamos que nos façam. Onde foram abordados os comportamentos, atitudes e relacionamentos.

- Motivação e influência: entende-se que a motivação é uma força ou impulso interior, podendo ser intrínseca, ou seja, vem de dentro para fora do ser humano e extrínseca que surge de fatores externos do dia-a-dia de dentro de uma organização.

- Custos: foi abordado os tipos de custos (fixo, variável, direto, indireto, custo de oportunidade e despesa), já que as atividades rotineiras são do setor Financeiro e Departamento Pessoal.

- Clima organizacional: Pesquisa realizada com três segmentos na empresa de serviços de saúde - com a finalidade de elaborar um plano de ação para que possamos identificar as anomalias e eliminá-las.

- Gerenciamento de tempo: para garantir que as atividades rotineiras terminem no prazo desejado, portanto fora do prazo pode gerar insatisfação dos clientes internos e externos, podendo assim aumentar os custos e a tensão da equipe.

Sendo assim foi colocado um pequeno quadro branco dentro do setor, para realizar pequenos treinamentos rápidos, conforme a Figura 8.

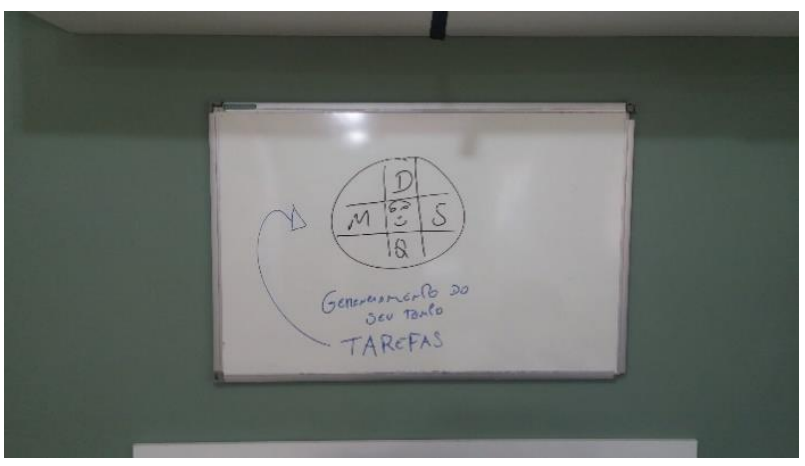

Figura 8: Quadro de treinamento no setor

Fonte: autor

A segunda causa, que se refere ao pessoal insatisfeito, tem como principal motivo a chefia, com exigências bastante elevadas, a mesma também fazia muita pressão sobre colaboradores devido a erros nas atividades realizadas por eles. Alguns funcionários tendo uma maior sensibilidade, não aguentavam tanta pressão do chefe, e quando erravam ocultavam os erros para não receberem reclamações.

Para sanar esta causa foi feita uma pesquisa de clima organizacional para saber o grau de satisfação dos colaboradores e, com os resultados ter uma melhoria e um bom relacionamento interpessoal.

A terceira causa, relacionada à inexistência de procedimento operacional ou um fluxograma mostrando passo a passo como executar as tarefas, impossibilitava a execução das atividades de forma completa e eficiente.

A solução foi elaborar um procedimento de operação das atividades junto com os colaboradores para que as tarefas realizadas seguissem um único padrão, caso algum colaborador esquecesse de como executar, poderia recorrer ao procedimento ou passo a passo, evitando-se tarefas mal executadas ou incompletas.

A quarta causa, referente falta de controle de qualidade das informações do setor, as informações externas que eram recebidas não eram registradas, e no momento que se fazia necessária a utilização das mesmas o acesso a elas se tornava bastante complicado e demorado.

Para sanar esta causa foi implantada uma rotina de procedimento de trabalho, de como seria feita cada atividade, tendo um maior cuidado para não sair erradamente do setor, fazendo treinando com o pessoal, unificando informações em uma mesma

http: / / dx.doi.org/10.25286/repa.v2i4.750 
plataforma de trabalho para ter uma visualização macro, facilitando assim as tomadas de decisão e, se houver erros, corrigir na hora, antes que as informações saiam do setor erroneamente. Tendo esse controle de conferência, verificação e indicadores, a qualidade das informações teve um grande ganho ao saírem do setor corretamente, e um dos treinamentos com os colaboradores serviu para passar a seguinte informação, onde foram dados os pesos aos erros, sendo: erros internos no setor é igual a: $10^{\circ}=1$, quando parte do setor para o outro setor é igual a: $10^{1}=10$ e quando parte para o cliente externo seria: $10^{10}=100$ onde envolve transtorno das partes, que um erro final vale cem vezes mais.

$\mathrm{Na}$ causa cinco do diagrama, que se refere a falta de um layout adequado, foram tomadas as seguintes ações corretivas: uma simples mudança de tirar uma mesa do setor e obter um espaço a mais, além de mudar o posicionamento dos colaboradores, gerou um ganho de produtividade.

A sexta causa: a falta de um sistema de pagamento online. A correção foi a implementação de um sistema do banco que realizasse múltiplos pagamentos ao mesmo tempo e isso teve um ganho grande na redução de tempo e na elaboração dos demonstrativos, evitou-se que os cooperados fossem na empresa receber em cheque ou até depósito. Anteriormente os pagamentos levavam 48 horas para serem creditados na conta, com a opção pelo método online os erros foram minimizados e o tempo de recebimento reduzido para 30 a 45 minutos.

Com as devidas causas mencionadas anteriormente, cada uma tendo suas ações e corrigindo-as, com o passar dos meses, foram analisados que os erros foram diminuindo como mostrado no Gráfico 1, onde apresenta informações que foram coletadas dentro do setor, entre os meses de outubro de 2016 a junho de 2017.

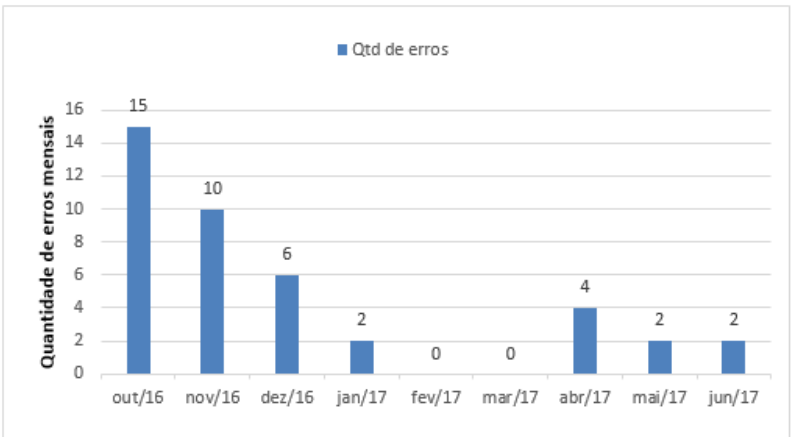

Gráfico 1: Quantidade erros mensais após implantar o controle de qualidade

Fonte: autor

Foi identificada a necessidade de colocar um quadro de Gestão à Vista, para que os principais itens de controle estivessem de fácil acesso para toda equipe do setor, seja através de dados, metas, cronogramas das atividades rotineiras, indicadores. Isso permitiu uma rápida e fácil visualização das informações, como mostra a Figura 9.

\section{Conclusões}

Este trabalho apresentou alguns conceitos da Gerência da Qualidade Total juntamente com as suas principais ferramentas.

Alguns dos conceitos foram aplicados em uma empresa que presta serviços na área de saúde, com a finalidade de sanar as principais falhas nos processos rotineiros, objetivando, assim, alcançar uma maior eficiência e eficácia no seu desempenho

Com o crescimento da demanda por colaboradores e uma grande rotatividade destes, percebeu-se que era necessário uma maior conferência e controle das informações utilizadas e das atividades realizadas dentro do setor Financeiro e Departamento Pessoal para uma maior eficiência dos serviços prestados.

Através das análises realizadas, foi possível perceber que ao passar dos meses os colaboradores internos precisavam de treinamento para que as atividades fossem executadas de forma padronizada por eles, seguindo um fluxo pré-determinado.

Viu-se que o TQM junto com as ferramentas da qualidade, não só aplica-se nas indústrias como também pode implementar e aplicar em qualquer empresa, inclusive de serviços, tendo como foco, a 
melhoria contínua, ou seja, fazer hoje melhor do ontem e fazer amanhã melhor do que hoje.

\section{Referências}

[1] CARVALHO, M. M.; PALADINE, E. P. Gestão da Qualidade: Teoria e Casos. 2. Ed. Rio de Janeiro: Elsevier: ABEPRO, 2012.

[2] ANTÓNIO, N. S; TEIXEIRA, A.; ROSA, Á. Gestão da Qualidade - de Deming ao Modelo de Excelência da EFQM. 2. Ed. Lisboa: Sílabo, Lda , 2016.

[3]

MOREIRA, D. A. Administração de produção e operações. 2. ed. ver. e ampl. São Paulo: Cengage Learning, 2009.

] SLACK, N.; CHAMBERS, S.; JOHNSTON, R. Administração da produção. 2. ed. - 10. reimpr. São Paulo: Atlas, 2009.

FEIGENBAUM, A. V. Total quality control. Mc Graw-Hill, 1986.

[6]

FERREIRA, R.R. O Kaizen como sistema de melhoria contínua dos processos: um estudo de caso na Mercedes Benz do Brasil LTDA planta juiz de fora. 2009. Monografia (curso de Secretariado Executivo Trilíngüe) - Universidade Federal de Viçosa, Minas Gerais. 2009.

CAMPOS, V. F. Gerenciamento da rotina do trabalho do dia-a-dia. Nova Lima: INDG Tecnologia e Serviços Ltda., 2004.

[8]

CHAIB, E.B.D. Proposta para implementação de sistema de gestão integrada de meio ambiente, saúde e segurança do trabalho em empresas de pequeno e médio porte: um estudo de caso da indústria metal-mecânica. Tese de Doutorado. COPPE/UFRJ, 2005. Disponível em:

http://www.abepro.org.br/biblioteca/eneg ep2009_tn_stp_091_621_14011.pdf>

Acesso em: 29 de maio 2017.

[9]

LUCIETTO, D. ; COSMA M. A.; ZANANDREA G.; CRUZ M. R. 40 Simpósio Científico FTSG. Ferramentas da qualidade Resumo. Disponível em: $<$ http://ojs.ftsg.edu.br/index.php/simposi o/article/view/21 > Acesso em: 29 de maio 2017.
[10] POLACINSKI et al. Gestão da qualidade: aplicação da ferramenta $5 \mathrm{w} 2 \mathrm{~h}$ como plano de ação para projeto de abertura de uma empresa. Disponível em: < http://www.fahor.com.br/publicacoes/sief /2013/gestao_de_qualidade.pdf > Acesso em 30 de maio 2017.

[11] FALCONI, Vicente. Qualidade: gerenciamento da rotina do trabalho do dia-a-dia. 3. Ed.

Rio de Janeiro: Bloch, 1994. 
Aplicação das ferramentas da qualidade em uma empresa de serviços de saúde da região metropolitana do Recife-PE

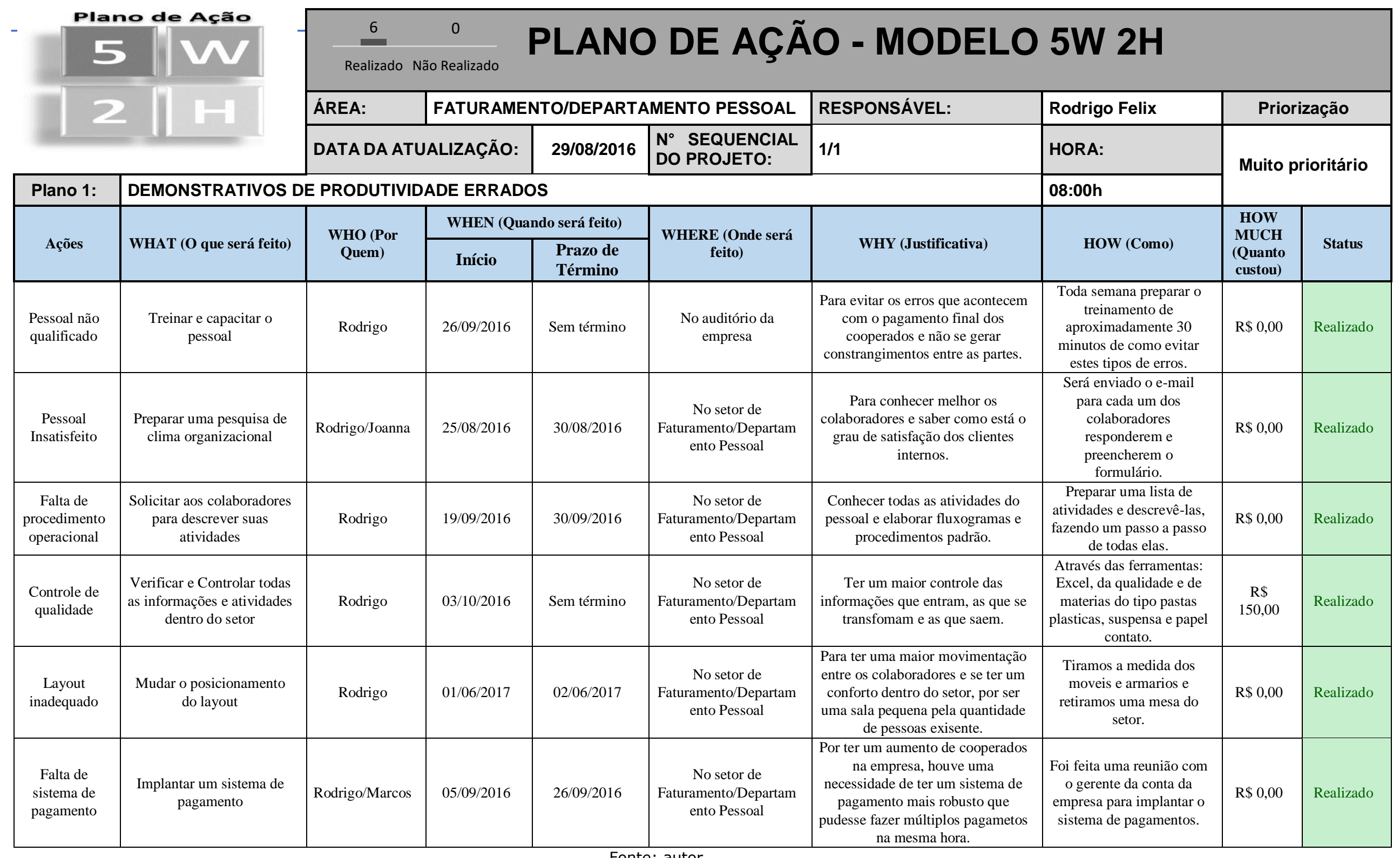

